ISO 9001:2008 Certified

International Journal of Engineering and Innovative Technology (IJEIT)

Volume 10, Issue 4, October 2020

\title{
The Ephemerality between the Scenographic and Monumental Architecture - Part II
}

\author{
Patrícia Diogo, Teresa Pinto
}

\begin{abstract}
Architecture, as a science, presents great visibility in urban spaces. Understanding the continuity from past shapes represent insights on ancient times, societies, one intends to analyze which factors determine such continuity. The main aim will be to consider architecture as a continuity element, emphasizing its position on urban settings, i.e., urban visibility. In the urban space, one finds the difference between what endured over time and new constructions. The current urban reality will then become the synthesis between transformations conducted on pre-existence or new constructions.
\end{abstract}

Beginning by framing an urban space with monumental relations and ephemeral representations, one intends to approach architecture under a broad perspective, while not overlooking theoretical and historical relations underlying to the place from a scholastic point of view and trying to analyze the architectures' work together with accumulated problems or transformations that take place with less theoretical and scholastic visibility.

Index Terms - Architecture, Monumental, Urban Space, Urban Voids.

\section{INTRODUCTION}

Thus, the permanence of monumental architecture is questioned, the type of architecture that has more scholastic, historical and physical analysis' elements. Historical monuments and centuries-old churches are, thus, spaces that representing other times and that have a great importance on public space for their difference and uniqueness. Recent monuments reaffirm the same objectives; they will become historical monuments on the future, which will represent lifestyles and cultural representations of today's society. One wants to achieve a broad analysis and, therefore, one wants to frame an anonymous architecture that represents a given function. Since there is no intention of distinguishing between common buildings from monumental buildings, the importance of this architecture is emphasized as a component of urban spaces, even if it has greater emphasis on functional and constructive aspects. One might consider these spaces to be less symbolic and more pragmatic, perhaps even as having less historic interest and less scholastic references, but they are also an integral part of development of architecture and an integral and essential part of urban settings.

We must also consider motivations that ephemeral architecture presents as a conceptual and constructive freedom factor, promoting utopias that trigger transformation times that hold new scholastic theories. To change via the ephemeral is both tempting and daring, since experimentation is easy and there is a much lesser expense of physical and temporal resources.

Manuscript received: 24 September 2020

Manuscript received in revised form: 16 October 2020

Manuscript accepted: 05 November 2020

Manuscript Available online: 15 November 2020

\section{CASE STUDY: MONUMENT OF DISCOVERIES}

The essential issue of this study is, thus, perceiving and knowing what the architect and populations in general feel towards urban context and their buildings. Similarly, one also questions the importance of the ephemeral in urban relations as a trigger for transformations. Ephemeral architecture has great potential to achieve and influence urban spaces which left behind an urban planning framework. The survivors of this urban transformation were a monumental public space and some buildings, which endured until now. One will study the examples within this monumental urban setting, with historical references to the golden era of the Portuguese Discoveries, which, from the 1940s have suffered changes in their urban setting.

On this situation, one wanted to complete one analysis already started in the first article. One particularly difficulty is related to the fact that it an ephemeral case in study was lost in time. The survival of some buildings that surpassed the limit of the ephemeral condition, established during their genesis, were the grounds for an early reflection. The Monument to the Discoveries held in Lisbon, Portugal was the most important ephemeral element: after its ephemeral time was concluded in the 1940's exhibition, it was rebuilt in permanent material 20 years later as we can observe in fig.1.

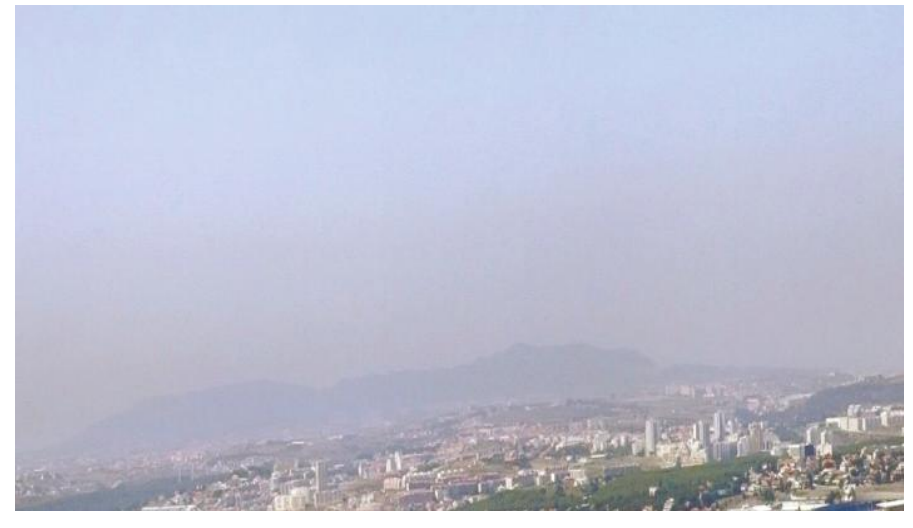

Fig.1.Panoramic view of Lisbon City with Discoveries Monument in center.

Also important was the transformation that took place on the public space, which put forward the potential for later constructions and that still left public spaces with great interest intact for the valorization of the space in itself and even Lisbon. Public space has monuments of more distant times, from the Portuguese Discoveries time, also relating it with the maritime expansion of Portugal. It is therefore essential to search, from these days onwards, for the reasons behind the first constructions to place the transformations that took place over time to better understand this space, the support for the case studies chosen, particularly the reasons 
ISSN: 2277-3754

\section{ISO 9001:2008 Certified \\ International Journal of Engineering and Innovative Technology (IJEIT) \\ Volume 10, Issue 4, October 2020}

behind the first monuments and church that determine, even today, a monumental reading of the space as we can study in fig. 2 that shows Jerónimos church in a red painting.

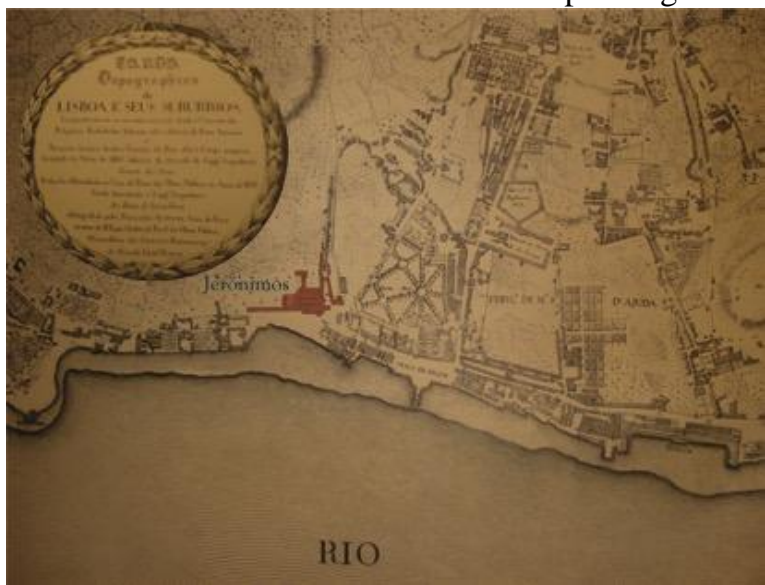

Fig. 2. Photograph taken in the meeting with Antonio Tudella from the book by Vieira gives Silva: Lisbon Atlas by Engineer Augusto in Topographic plans of Lisbon - Vieira gives Silva ATLAS - CML, 1950; commemorative edition of the eighth centenary of the capture of Lisbon from the Moors.

In this urban space illustrated in fig. 3 and 4 , part of the result of the Centennials Exhibition, one chose the Monument to the Discoveries because it accomplishes the desired monument to Prince Henry, the Navigator. Currently, it is an icon of the city of Lisbon and a symbol of the Portuguese Discoveries.

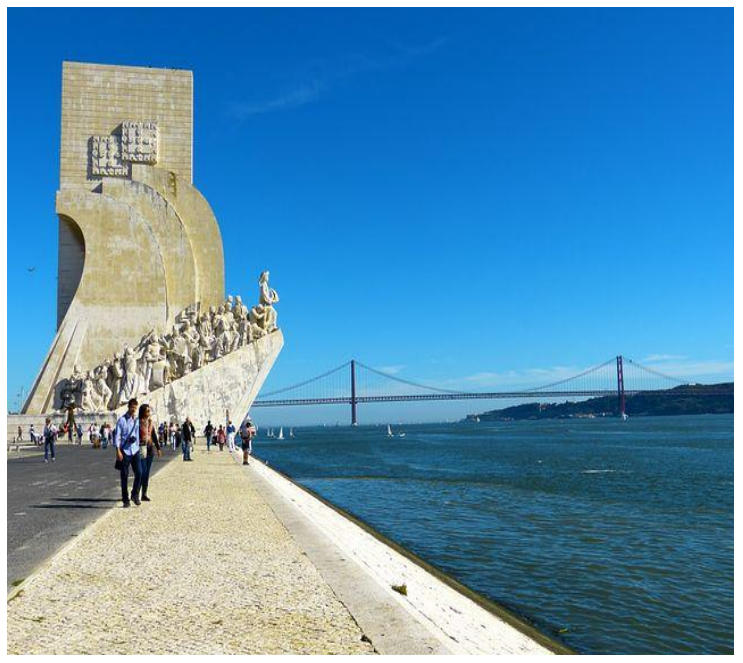

Fig. 3. Pattern of Discoveries

This example was chosen because it is a part of the Exhibition of the Portuguese world (and thus an evolution of earlier studies) and also because they question the continuity of architecture throughout time and reasons behind that continuity. while trying to understand the values that architecture holds within the urban space, between monumental and ephemeral values, these examples contextualize the time that passed from 1940 until today of a building that fulfilled a national objective - the creation of a Monument in honor of Prince Henry a pragmatic building and the reuse of pavilions to create the Museum of Popular art, building that will be studied in future investigation.

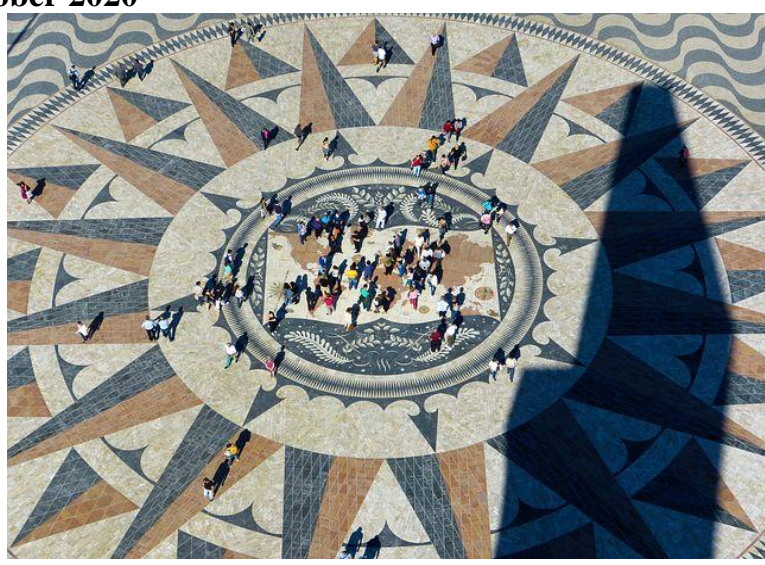

Fig. 4. Public space in front of Monument to the Discoveries

The study of the life of such buildings has not yet been conducted and it will be important to contextualize architecture's and artistic values in a place that goes by the name of Belem. The Monument that justifies the option to organize the Exhibition of the Portuguese world on that location the Hieronymites is essential to understand the identity of the place. It is part of the scenario for the Centennials' Exhibition and an essential element towards the urban alterations that occurred with the exhibition.

\section{SPACIALITY: LINK IN BETWEEN}

One does not intend to describe the story behind a place called Belem nor behind its monuments or architectures, but rather to try to understand the built reality, using a qualitative and synthetic approach.

What we see now is the result of the sum of individual actions, a sum that cannot be fully known. The life of buildings and cities lies between the selectiveness and the synthesis ability that become real through matter whether by shapes or by the understanding and interpretations the same matter has. The meaning of architecture since Genesis becomes different; with time, different meanings come forward, while others remain undeciphered. What we designate as the cultural identity of places and architecture is neither constant nor linear.

In a few words: one omits several data if one places the erected over a vast time starting by relating the details behind a concrete phenomenon and what is visible now; on the other hand, other disciplines may infer other knowledge about the place, its story, its experiences, policies and even public opinion, economy and the relative interest of several groups, among other factors which architecture and public space are related in different approaches.

One must not forget some people who had a crucial part in the decision-making process, but one will also try to introduce other, anonymous citizens, important in the relationship between place and the erected.

Michel Foulcault stated that history is a 19th century obsession, an obsession with accumulating the past, which threatens the world's glaciations and he justifies that our age will be an age of space, "an age of juxtaposition, of proximity and remoteness, of side- by-side and of disperse"[5]. 


\section{| \\ ISSN: 2277-3754 \\ ISO 9001:2008 Certified \\ International Journal of Engineering and Innovative Technology (IJEIT) \\ Volume 10, Issue 4, October 2020}

One understands that space has a complex relation with history. The same has distinct meanings in different periods of time, because the understanding regarding what is built is also a work in progress and, thus, a different presentation (interpretation) could possibly condition future understandings (interpretations). In this sense, one does not endeavour to perform history but rather to contribute towards the understanding of and for the cohesion of shapes with different buildings within a single public space, linking heritage with tectonic relationships within a scholastic level of what the architecture is and their professional restraints.

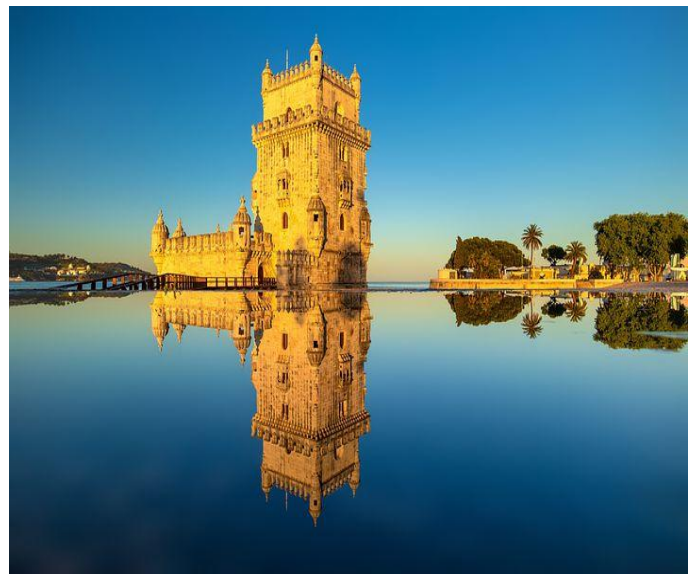

Fig. 5. Belem Tower in Lisbon, Portugal

Policies do not always have a direct influence over the erected works, but they always condition them. Only a few have responsibility over the legislative aspects, who, without any specific knowledge, conditioners architecture and city space. The architect is not alone in his / her decisions, but he / she models the space and time through sketches and through the construction, between searches for processes, languages of new meaningful representations or simply to build. In history, architecture gains meanings and uses different from those initially set; new symbolic values that present culture and the identity of a society which reuses and grabs a hold of space and architectonic objects. For symbolic values, new meanings are given or one fails to decode the previous meanings; as for functional values, the appropriation of spaces and shapes is not always pacific. The genesis of monuments and the buildings on that place will be analyzed, either their changes, either the demolitions. It is also important to mention the projects that failed to be erected; the records made show research methods of shapes, of answers to determined intents of transformation. In this sense, some events will be compiled, some wills in different social and political backgrounds which influence a methodology for the framing of architecture as a discipline or as part of a culture.

One also wants to understand a collective identity in this space, an identity which symbolizes the people behind a nation, which initiated from here the discoveries, with the illusion of constructing a new world. The meanings acquired since its origin lie in a superior level as a reference, between the city of Lisbon as capital of Portugal and the opportunity for extra-national relationships, which are made explicit not only by the economical, political or religious relevance, but also by the interpretation that Man has of his relation with the World. This sense of national identity is not only perceived by the physical reality, but also by the monuments that kept this record. It is important to understand the questions of architecture revealed by time's physical changes, framed in projects. An architect's working method is inconstant, ranging between the classical (norm or model) to the 'emotional' (gothic or symbolic), radical (utopian or evolutionary) to the conservative (traditional or typological), but it is also always original. Nevertheless, one works with what one knows and with what one retain from pre-existences (physical/technological or cultural) and, in this sense, one intends to make a contribution towards the architect's methodology. The question put forward, which does not necessarily need to have an answer, is related to the concerns of the durability of buildings. The selection made for further analysis is only a small fragment, much is left unsaid but it is crucial for the framing of durability in architecture or, to better explain this, with the cultural values that influence the permanence of buildings regardless of their resistance or absence to resistance to change. This place and these architectures will serve as the framework for the previously mentioned discussion.

\section{THE PLACE}

The symbolism of the place is due, first, to its geography, meaning to the natural conditions of this location exposed in image 1 and 2. Located at the western part of Lisbon city, it has a soft climate, which, together with a fertile soil and the existence of drinking water, would allow for the existence of archaeological settlements, starting from the Lower Paleolithic [4]. In the space surrounding the Monastery's enclosure, lived a small settlement occupying semi-circular space until the beginning of the Iron Age, of which there is no knowledge over what caused its extinction or of its posterior influence [4].

"Tagus estuary, that strong embrace between the sea and the land" was determinant for the relationship of Portugal with the sea and from here with the World [5]. The sea was important in defining the country's limits and its history; this place near the Tagus was a starting point for the dream that broke ground towards the discoveries. The Tagus has an increased importance because the discoveries started through it and, on a second stage, it will favor the development of economy by the carriage of goods.

The ideological and symbolic association given to this place is also due to the religious importance, a presence ever since the first chapel dedicated to Our Lady of the Stars was built in 1448 by Prince Henry the navigator, on the sandbanks of Restelo. On this port, Prince Henry thought of the need for a chapel to provide spiritual comfort to several Christians who got ashore there and he also thought of building a "water conduct and spring and fountain" [3] to provide support to everyone. Prince Henry the navigator and other seafarers used to pray before setting sail.

King Manuel I reinforced this relation with the holy by 


\section{|DEET \\ ISSN: 2277-3754 \\ ISO 9001:2008 Certified \\ International Journal of Engineering and Innovative Technology (IJEIT) \\ Volume 10, Issue 4, October 2020}

constructing an enormous monastery and church in honour of the Hieronymites and really intended to put forward reasons towards the understanding of this space as a place of initiation.

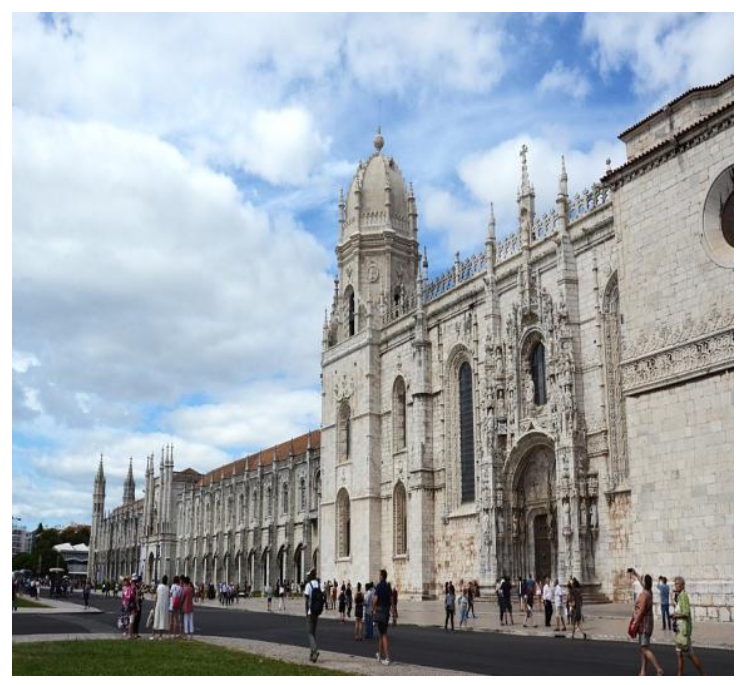

Fig.6. Jeronimos Monastery

With the construction of Jerónimos Monastery in the image 6 , the settlement grows and even the architects John from Castilho and Jeromino from Ruao set up residence near the main chapel, in what would later become the Palace of the dukes of Aveiro, destroyed in 1759 [4]. Since the 16th century, it became a place of reference for noble villas and houses, because it was near Lisbon and provided for a good quality of life. Lisbon's urban nucleus was located five kilometers from this small dock on Tagus' riverbank. The people appeared to be more concentrated on the hill called Restelo.

In 1940 , the country celebrated here eight centuries of history, with the Exhibition of the Portuguese World. This Exhibition reinforced the signs of that representation, through a plan which restructured public space and acted as an impulse or starting point of a new possibility towards new constructions and uses. The main study cases in analysis were conceived for this exhibition and sit on the Tagus' riverbank, facing Hieronymites Monastery.

Now, the city has assumed an identity figures in this small space as an ancient metaphor which determined political relevance and the assertion of an entire country abroad. A space that justifies the existence of an entire nation, through the specificity of a national architecture, epitomized in Jeronimos' Manueline style. Monuments, whether historical or not, represent the city's and the country's collective identity, as well as having a considerable prominence.

Considering this was a place outside the central urban city nucleus, where housing had only a little representation, it does not conform to Marc Auge's definition of place "as identifying, relational and historical" [3]; it rather has an opposite polarity which allowed for an extra-national mobility. It was indeed the non-place, the starting point of the waterway and, from here on, to the African coast and to the 'discovery' of India. This place was never important for its social relation, for the permanence or for the dwelling, for the identification a specific group; it was not the place for human permanence, but rather a place of start and external relations. It represents the symbolism related to the discoveries, as the point of departure and destination of exotic goods coming from the "new found land", acquiring symbolic and spiritual relations.

From the 16th and 17th centuries onwards, along with some industrial development, it become an important port of exports. On the 19th century, with the construction of a bigger embankment, a road and the railway track, the travels from and to Lisbon were improved but the relation with the river was cut.

It now integrates the definition of place, it became "promoted to "a place of memory" . of the golden age of the discoveries and, in the future, it will gain new representation, if one bears in mind the increasing values of cities with natural elements, in this case, the relationship with the river is not yet settled.

One intends to perceive the 'genius loci' [3]. of Belem by making a synthesis of the several understandings in its history. Its structure was altered, the identity also gained new meanings and many are difficult to understand now. The natural place was a beach or a small dock which allowed for the departure towards the Tagus [3].

The beach no longer exists and the caravel's sail is represented by a metaphor in the Monument to the discoveries, in what was called 'the sense of departure' during the Exhibition of the Portuguese World. The space is no longer natural, it bears a different configuration, it was transformed, built, it is artificial. The construction is of architecture but also of space won over the river.

Over this matter, the question emerges between the preservation of genius loci for a great period of time by preserving fundamental aspects of the meaning and of the identification of a place or the possible preservation of genius loci through new functional and symbolic relationships.

In urban space and constructions, the wills of many are represented but there is also the absence of events that individual and collective memory failed to emphasize or hid. It is considered a cultural place, tourism oriented, which is a fundamental part of its current daily life. Nevertheless, tourists visit this place and its monuments in under a day. One must not forget that this place also acted as the support of ancient times and other experiences between generations with different attitudes and between different policies, in a non-linear and non-pacific relationship.

Between the riverside space and the space facing Jeronimos, there is some separation, if one considers the barrier built the railway track. On the other hand, the monumental scale of urban space cannot be related to their daily use or to common uses. The common uses on a small urban scale lie in lateral spaces.

The Cultural Center from Belem occupies a fundamental urban position, the Jeronimos' church a religious (and touristic) function, museums a cultural importance, even 


\section{ISSN: 2277-3754}

IUEIT

ISO 9001:2008 Certified

\section{International Journal of Engineering and Innovative Technology (IJEIT)}

Volume 10, Issue 4, October 2020

greater in an urban context, where figures metaphors of what is built take on diversified meanings for all because they are superficial.

\section{CONCLUSION}

As a synthesis, one might declare that, between transformation and permanence of architecture, one questions the discipline's methodology and its implications within public space. One looks for the reasons behind differences in meaning and public visibility and the values (not always obvious) to understand the importation of the options made by architects in daily work. Tectonic options may have a formal important demand or they may be reduced to small alteration, often anonymous. Nevertheless, the set often triggers substantial alterations.

Underlying, the study of architecture from a human point of view, e.g., to understand the motivation that drove alterations. The human material materialization capabilities. Sometimes, architecture is considered to be anonymous, with no historical value, alienated from the situations that are repeated in quantity throughout the cities; nevertheless, it always presents more of the cultural values of the places and also calls for careful analyses of the design and alteration proposals. In this sense and within an urban context, architecture has distinctive readings and from that assumption, this study was born.

\section{REFERENCES}

[1] Ignacio Canas, Silvia Martin, "Recovery of Spanish vernacular construction as a model of bioclimatic architecture", Building and Environment, 39(12), pp: 1477-1495, Dec 2004.

[2] ROSSI, Aldo,"The architecture of the city", Gustavo Gili., Barcelona, pp.81-82, 1982.

[3] SHULTZ, Norbert Christian,"Genius Loci: Landscape, Ambiance, Architecture", Pierre Mardaga editor, Liege, pp: $1-18,1981$.

[4] CARDOSO, Antonio Jose by Andrade Munoz,'Urbanism and Architectures - Lisbon of the Discoveries", Phd Thesis in Technical University of Lisbon, Lisbon,pp:1-119,1995.

[5] ROSA, Walter in Belem Cultural Center, "Invitation to tender for the Project of Belem Cultural Center", Catalog, Lisbon, Portuguese Institute of Cultural Heritage, pp: 1-124,1989.

\section{AUTHOR BIOGRAPHY}

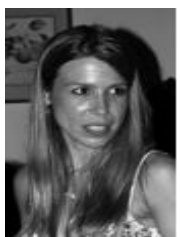

Diogo, Patricia was born in Oporto, Portugal in 10th June of 1980. In 2009 she defended her Doctoral Thesis in Higher Technical School of Architecture in the University of Valladolid with the title "Rural Nuclei: a manifestation of authenticity recognized in Portugal by Oporto University. She is $\mathrm{PhD}$ and Auxiliary Professor of University Lucida North in Architecture Department and Master Program and Researcher in CITAD.

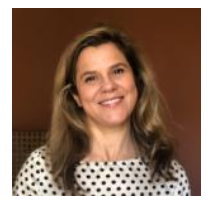

Pinto, Teresa was born in Vizela in 26th August of 1972. In 2012 she defended her Doctoral Thesis in the University of Manchester with the title "Belem:
Monumental Space in Lisbon among the Glimpse of the Ephemeral "She is $\mathrm{PhD}$ and Auxiliary Professor of University Lucida North in Architecture Department and Master Program and researcher in CITAD. 